\title{
El camino de la poesía \\ en el tiempo del fuego generalizado. \\ Evocaciones a poemas de Daniel Jiménez
}

\author{
Eufrasio Guzmán Mesa* \\ https://doi.org/10.22395/csye.v7n13a9
}

Como cae una gota de lluvia sobre la piedra, así empieza la palabra su camino, viajando desde la flor que puede nacer en la lengua, hasta la semilla interior que gobierna nuestro crecimiento desde el pecho. Del profundo mar a la playa, de la playa al árbol, de la copa del árbol al centro de la tormenta, luego va a la lluvia para retornar a la ola que no cesa. El tránsito de lo viscoso a lo aéreo, del filamento al huevo crepitante, se marca con la uña calcinada en la piel del sueño.

Todo puede empezar como un grito o una triste declaración de amor a una ventana, lo importante es que se haya decidido arrebatar el designio al hastío y denunciar la impostura de la propia palabra: "Sabes que es mentira / tu odio, que tu sed es mentira".

La palabra como la mentira primera es el primer baluarte que derribará el artista en su guerra con el silencio de basalto y tierra negra en la boca. "Que esas mentiras sean tu / antorcha, tu espejismo para la vida". Voz de las fauces que emprenden su lucha por la expresión de ese dilema original: respiran la arena, comulgan con la hostia de ladrillo de los desposeídos, tendrás que dar el testimonio de la consistencia última de tus huesos.

$\mathrm{El}$ reto nace con la conciencia que se erige desde la vida atenta a su curso delirante. No hay un sentido, no hay sentido en el sufrimiento, no hay velamen que nazca en nuestro pellejo descuartizado, requerimos el agua de la vida, la esperanza en el aire tibio de un sol que nos abraza para emprender el canto. Sin este mar que arde en la espalda y consume los tejidos del cuello, no valdría la pena el arrojo y el esfuerzo por hacer accesible y circulante la esperanza ciega.

La humanidad parece no escuchar, por momentos ni siquiera los iguales advierten la agitación esencial y ese tránsito de nube a roca, de cristal a humo que asciende cuando respiramos.

Algo de plasma inerte, exhalación final y grito desesperado parece albergarse en cierto brillo de la mirada. Hace falta el milagro de la sublevación del agua, la lluvia devolviéndose en remolino, retornando a la cresta blanca de la

Licenciado en Filosofía y Letras de la Universidad de Antioquia (Colombia) y profesor del Instituto de Filosofía de la misma universidad. Correo electrónico: tirtamo@hotmail.com 
montaña, para que así podamos emprender la peregrinación al punto en el cual el murmullo se vuelve plegaria, invocación o poema.

Por un camino inverso, la palabra retorna a su fuego milenario, se confunde con un magma primordial que se agita con incandescencia antes que nosotros, en el instante mismo del comienzo del universo.

Siempre podremos volver a poner el oído sobre la tierra de nuestros sueños, para captar el momento en que unas ansias más viejas que el primer tiempo, se volvieron vibración consonante con la oscilación de un agua sideral en nuestro cuerpo. La rabia ciega, la ira, la imprecación y el insulto comparten con el gemido y el llanto ese origen milenario que compartimos con el volcán en erupción, con el nacimiento del agua, con el aire que maneja la arena.

En el poeta hay una edad feliz, sin tiempo, en la cual todo esto se repite en la lengua, como una visión diabólica que impregna la mañana. Rugía anoche en la memoria, en una evocación de filo y guadaña de la muerte, concede ahora todas las ternuras con el alba y es como si volviéramos a empezar desde cero el conteo interminable en el lago de las horas.

Cada amanecer es posible por "una tregua feliz con el mundo", pero en el curso del día, como un escalpelo que nos lastima y desintegra, las manchas de la noche establecen un gobierno minucioso de la sombra. Para la vivencia expresada en los poemas de Daniel Jiménez, somos dioses muriendo en medio de un desatino: "que a ti el desprecio te llegue / como la guirnalda de un dios que se desangra".

Hay en estos poemas el registro de un hilo que en cada ser recomienza: Ícaro con sus alas vulnerables o Etana que sobre un caballo blanco persigue el cenit del cielo azul de Babilonia. A esos caminos hacia la ascensión, a los pasos de quienes asumen el reto de la etnografía interior o el aclaramiento del horizonte, Daniel Jiménez les agrega algo: en la ignominia, en la caída, en el extravío, una reclamación, un grito de dolor y de impaciencia cuando se experimenta como único y oprobioso ese camino.

La palabra originaria, la imprecación, el insulto y el canto, al parecer el poema también, obedecen a un movimiento que olvidamos. Todo se dispersa, se eleva con agitación y permanencia como un polvo sideral que nos fija al fondo de las estrellas. La poesía intensa nos recuerda a cada instante ese proceso. Ella es visitación de la turbulencia y relación de un devenir que parece excedernos. Al final, para nuestra alegría y salvación, también retorna al plato que recibe la sangre de las desolaciones. En el caso de la poesía de Daniel Jiménez, el poema abreva de esa linfa gélida que anuncia la paradójica consistencia de la mañana. 
Daniel Jiménez se pregunta y busca el rasgo esencial de su estirpe. Lacerado, mutilado, ávido y contrito busca el agua pura que destila su fuego. Esta experiencia del desgarramiento y la herida nos pide cuenta del más remoto origen del silencio y la palabra. Ante el dolor, el sufrimiento y la soledad hay que ofrecer a todos, y entregar a sus iguales la prueba descomunal del testimonio en la carrera atropellada.

Perseguidos en medio del bosque y en descubierto, siempre anhelando saber del hilo que gobierna los vientos. El poeta viene advirtiendo la corrosión del olvido y la huella de otra sangre seca en el río de nuestra memoria. Por eso, nos pregunta y se interroga en un vaivén de negar y aceptar el trago amargo y por ello, también reclama un firmamento más denso y, paradojas del poeta, además más transparente.

El poeta que encarna y calcina, Jiménez nos recuerda que se requiere el fino pulso del marino para mantener un norte y sobrevivir a los momentos en los cuales todo parece contener la saliva ácida de una mentira y el vaho mortal de una venganza cuyo origen desconocemos.

La poesía en muchas voces asigna el sentido mediante una operación de asiento y entrega. También la poesía explora, hurga y desgarra una convención que se hace trizas ante la pregunta vuelta laceración y daga, este es el caso del trabajo de Daniel Jiménez. Él avanza entre un gesto titánico que lo sacrifica y lo resuelve, navega en un juego de palabras que contienen la conducción de su "navío al filo del riesgo".

Palabras para pagar un secreto y remediar el silencio de un instante. ¿Con qué palabras puede el poeta pagar el silencio de un momento? Cuando el torbellino del verbo se ha vuelto ademán de todos los instantes, arboladura y velamen para la navegación en medio de un fuego cruzado, queda el sabor de una saliva envenenada, las "gotas de ámbar son ahora tus arterias" y una sensación de derrumbamiento, de derrota implacable, de reinicio en el desastre que salva, por paradójica inmersión, al poeta:

En el sitio que buscas, una mano
dormida en la gangrena
cierra la puerta irrevocablemente.

Palabras y poemas para reintentar desde la soledad un nuevo trueque. Así podrá donar, a quienes "subastan tu vida / por treinta certezas", la evidencia del más resplandeciente de los ardimientos: el que nace del corazón herido por la sangre derramada, por el fuego que no cesa. También ese rendimiento es el que 
emerge de "tus ojos abrevando de la vida ese delirio", el cual -con abundancia iracunda- este poeta nos entrega, mientras permanece en la parte alta de la ola, adherido a esta nave a la cual nos invita a pasar, si el crujir de las duelas no nos espanta y nos conduce al silencio total o a la entrega sin condiciones al olvido. 